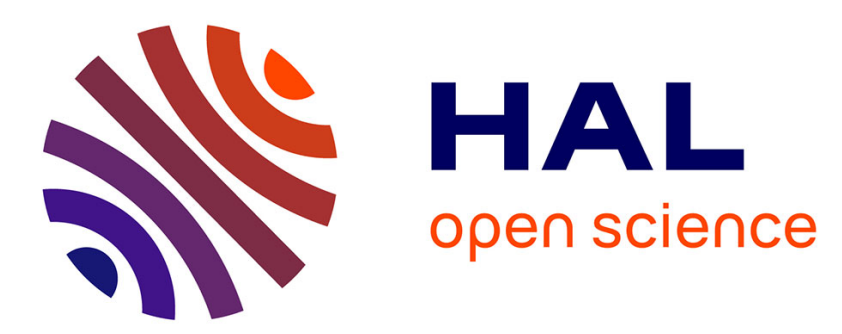

\title{
Dynamic interactions between apex predators reveal contrasting seasonal attraction patterns
}

\author{
S. Périquet, H. Fritz, E. Revilla, D. Macdonald, A. Loveridge, G. Mtare, \\ Marion Valeix
}

\section{- To cite this version:}

S. Périquet, H. Fritz, E. Revilla, D. Macdonald, A. Loveridge, et al.. Dynamic interactions between apex predators reveal contrasting seasonal attraction patterns. Oecologia, 2021, 195 (1), pp.51-63. 10.1007/s00442-020-04802-w . hal-03425858

\section{HAL Id: hal-03425858 \\ https://hal.science/hal-03425858}

Submitted on 11 Nov 2021

HAL is a multi-disciplinary open access archive for the deposit and dissemination of scientific research documents, whether they are published or not. The documents may come from teaching and research institutions in France or abroad, or from public or private research centers.
L'archive ouverte pluridisciplinaire HAL, est destinée au dépôt et à la diffusion de documents scientifiques de niveau recherche, publiés ou non, émanant des établissements d'enseignement et de recherche français ou étrangers, des laboratoires publics ou privés. 
1 Dynamic interactions between apex predators reveal contrasting seasonal attraction patterns

2

3 Périquet, $\mathrm{S}^{1,2,3^{*}}$, Fritz, $\mathrm{H}^{1,2,4}$, Revilla, $\mathrm{E}^{5}$, Macdonald, $\mathrm{DW}^{6}$, Loveridge, AJ ${ }^{6}$, Mtare, $\mathrm{G}^{7,8}$ \&

$4 \quad$ Valeix, $\mathrm{M}^{1,2,6}$

$6 \quad{ }^{1}$ Laboratoire de Biométrie et Biologie Evolutive, CNRS UMR 5558, Université Claude Bernard Lyon

7 1, Bât Gregor Mendel, 43 Bd du 11 Novembre 1918, 69622 Villeurbanne cedex, France

$8{ }^{2}$ LTSER France, Zone Atelier "Hwange", Hwange National Park, Bag 62, Dete, Zimbabwe - CNRS

9 HERD (Hwange Environmental Research Development) program

$10{ }^{3}$ Ongava Research Centre, Private Bag 12041, Suite No. 10, Ausspannplatz, 9000 Windhoek,

11 Namibia

$12{ }^{4}$ REHABS, CNRS - Université Lyon 1 - Nelson Mandela University, International Research

13 Laboratory, George Campus, Madiba Drive, George, South Africa

$14{ }^{5}$ Departamento Biología de la Conservación, Estación Biológica de Doñana (CSIC), Calle Américo

15 Vespucio 26, 41092 Sevilla, Spain

$16{ }^{6}$ Wildlife Conservation Research Unit, Department of Zoology, University of Oxford, Recanati-

17 Kaplan Centre, Tubney House, Abingdon Road, Oxfordshire OX13 5QL, United Kingdom

$18{ }^{7}$ Zimbabwe Parks and Wildlife Management Authority, PO Box CY140, Causeway, Harare,

19 Zimbabwe

$20{ }^{8}$ Kavango-Zambezi Transfrontier Conservation Area (KAZA TFCA)

$22{ }^{*}$ Corresponding author: stephanie.periquet@gmail.com

\section{Authors' CONTRIBUtions}

SP and MV conceived and designed the study; SP collected the hyeana data and AJL and DWM provided the lion data; SP analysed the data; SP and MV drafted the manuscript. All authors critically contributed to revised versions of the manuscript and gave final approval for publication. The authors declare that they have no conflict of interest. 


\section{AbSTRACT}

24 Apex predators play important roles in ecosystem functioning and, where they coexist,

25 intraguild interactions can have profound effects on trophic relationships. Interactions between

26 predators range from intraguild predation and competition to facilitation through scavenging

27 opportunities. Despite the increased availability of fine-scale GPS data, the determinants and

28 outcomes of encounters between apex predators remain understudied. We used simultaneous

29 GPS data from collared spotted hyaenas (Crocuta crocuta) and African lions (Panthera leo) in

30 Hwange National Park, Zimbabwe, to determine the environmental conditions of the

31 encounters between the two species, which species provoked the encounter, and which species

32 dominated the encounter.

33 Our results show that encounters between hyaenas and lions are mostly resource related (over a

34 carcass or around waterholes). In the wet season, encounters mainly occur at a carcass, with

35 lions being dominant over its access. In the dry season, encounters mainly occur in the absence

36 of a carcass and near waterholes. Movements of hyaenas and lions before, during and after

37 these dry-season encounters suggests two interference scenarios: a passive interference

38 scenario whereby both predators attracted to waterholes but lions leave a waterhole used by

39 hyaenas because of prey disturbance, and an active interference scenario whereby hyaenas

40 would actively chase lions from waterhole areas, which are prime hunting grounds. This study

41 highlights the seasonal dynamics of predator interactions and illustrates how the relative

42 importance of negative interactions (interference competition during the dry season) and

43 positive interactions (scavenging opportunities during the wet season) shifts over the course of

44 the year.

46 Keywords: African lion, carnivore intraguild interactions, Crocuta crocuta, Panthera leo,

47 spotted hyaena 


\section{INTRODUCTION}

51 Apex predators, through their effects on the abundance, distribution and behaviour of their prey

52 and mesopredators, have a profound influence on the functioning of communities and

53 ecosystems (Ritchie and Johnson 2009; Ripple et al. 2014). In most ecosystems, several

54 species of apex predators coexist. Understanding the functioning of their guild is key if we

55 want to grasp the full impact of the changes in the abundance and distribution of apex predator

56 populations that occur worldwide (Ripple et al. 2014; Chapron et al. 2014). Intraguild

57 interactions amongst predators are diverse. Negative interactions have been the most studied,

58 with predators not only competing through depletion of common prey but also posing threats to

59 each other through kleptoparasitism (Höner et al. 2002; Trinkel and Kastberger 2005) and

60 direct interference during aggressive interactions with risk of injury (Linnell and Strand 2000)

61 and intraguild predation (Palomares and Caro 1999). These negative interactions can cause

62 subordinate species to spatially and/or temporally avoid dominant ones (Durant 2000; Vanak et

63 al. 2013), similarly to the ecology of fear in predator-prey interactions (Courbin et al. 2013;

64 Palmer et al. 2017; Kohl et al. 2019). However, this is not always the case, and evidence has

65 accumulated on the absence of spatial and temporal avoidance between sympatric apex

66 predators (Cozzi et al. 2012; Miller et al. 2018). This absence of spatio-temporal avoidance

67 may be due to the fact that (i) avoidance mechanisms occur at very fine spatio-temporal scales

68 (Broekhuis et al. 2013; du Preez et al. 2015; Swanson et al. 2016) and often go undetected, (ii)

69 dominance is dynamic with the outcome of an interaction depending on the relative group size

70 of each of the competing species (Cooper 1991), and (iii) coexisting apex predators also benefit

71 from positive interactions between them. Positive effects of interactions have been less studied

72 and underestimated in community ecology (Bruno et al. 2003). They range from scavenging

73 opportunities (feeding from a carcass, Wilson and Wolkovich 2011) and kleptoparasitism

74 opportunities (displacing a competitor from its kill, Krofel et al. 2012) to indirect facilitation 
75 whereby prey, through anti-predator behavioural adjustments to minimize the risk of predation 76 by one predator species, become more vulnerable to another predator species. For example, elk

77 (Cervus elpahus) shift to habitats that have a more complex structure to reduce predation risk

78 from wolves (Canis lupus), which significantly increases predation risk from pumas (Puma

79 concolor, Atwood et al. 2009).

80 A pair of sympatric apex predators is not characterized by one type of interaction only, and

81 different, sometimes contrasting, interactions may occur. First, different interactions may

82 operate at different scales. Sivy et al. (2017) revealed negative responses of several carnivore

83 species to wolf abundance at the landscape scale (overall lower occupancy probability in

84 presence of wolves), but positive responses of the same species to localized wolf activity

85 (increased detection probability of coyote, Canis latrans, closer to wolf GPS clusters). Second,

86 the environmental conditions and the life history traits of the species may also determine the

87 relative costs and benefits of engaging in one type of interaction, which is illustrated by the

88 seasonal dynamics of some foraging tactics, such as scavenging (Pereira et al. 2014). Many

89 studies inferring negative or positive interactions between sympatric apex predators have been

90 conducted at the large scales of static interactions, focusing on the relative local abundance and

91 temporal niche of the predators (e.g. Schuette et al. 2013; Swanson et al. 2014; Sivy et al.

92 2017; Miller et al. 2018; Rasphone et al. 2020). These large-scale studies can only focus on

93 predictive responses to potential interactions, while fine-scale studies are necessary to

94 understand the reactive responses to actual encounters between apex predators. Little is known

95 on the fine-scale dynamics of inter-specific interactions due to the challenges of

96 simultaneously monitoring large carnivores, but some pioneering research has started (for

97 prey-predator relationships see Courbin et al. 2016; for apex predators intra-specific

98 interactions see Jordan et al. 2017; or Broekhuis et al. 2019; for apex predator interspecific

99 interactions see du Preez et al. 2015). The simultaneous GPS-collaring of sympatric apex

100 predators can provide information on the direction and speed of a carnivore's movement with 4 
101 respect to the other carnivore involved in the interaction. GPS-tracking has therefore the

102 potential to reveal which species is attracted to or avoid one another, and under which

103 circumstances.

104 In African savannas, African lions (Panthera leo) and spotted hyaenas (Crocuta crocuta) are

105 the two most common large predators and evidence has accumulated on the richness of their

106 interactions. These were reviewed by Périquet et al. (2015a) and it was shown that the

107 coexistence of spotted hyaenas (hyaenas hereafter) and lions is a complex balance between

108 negative (exploitative competition for prey, kleptoparasitism, aggressive interactions and direct

109 killing) and positive interactions (scavenging opportunities). Périquet et al. (2015a) highlighted

110 the need for the study of the spatio-temporal dynamics of these interactions. Here, we used data

111 from GPS-collars deployed simultaneously on lions and hyaenas to (i) identify the encounters

112 between the two species based on the proximity of simultaneous GPS locations, (ii) assess

113 which species provoked the encounter by approaching the other one, (iii) determine which

114 species was dominant during the encounter and triggered the displacement of the other species,

115 and (iv) identify when one species attempted to avoid the encounter by moving away from the

116 other one. We further evaluated the environmental conditions in which encounters occurred.

117 First, waterholes act as prey hotspots in arid and semi-arid savannas (Valeix et al. 2009; Valeix

118 2011), so we expected encounters to occur mainly close to waterholes. Second, African arid

119 and semi-arid savannas are characterized by contrasting (wet and dry) seasons. Large herbivore

120 body condition is highest in the wet season, when plant productivity peaks, and decreases as

121 the dry season progresses (Owen-Smith 2002). Hyaenas are cursorial hunters, i.e. chase down

122 their prey over long distance (Kruuk 1972; Mills 1990), and are therefore more likely to kill

123 weak individual prey. Their hunting success is thus likely to be lower in the wet season when

124 prey body condition is high. These seasonal variations in prey vulnerability to predation

125 provided us with a good opportunity to assess the temporal dynamics of hyaena-lion

126 interactions. 
127 Lions are the main cause of mortality for adult hyaenas and are expected to be dominant at

128 most encounters, especially when an adult male is present (reviewed in Périquet et al. 2015a).

129 Hence, we expected hyaenas to generally avoid encounters with lions and flee from an

130 encounter when it occurs, except in the wet season when prey are scattered through the

131 landscape and in good condition and therefore more difficult to kill and when hyaenas should

132 actively search for kleptoparasitism/scavenging opportunities from lion kills.

134 MATERIAL AND METHODS

\section{$135 \quad$ Study area}

136 Hwange National Park (HNP) is located in north-western Zimbabwe $\left(19^{\circ} 00^{\prime} \mathrm{S}, 26^{\circ} 30^{\prime} \mathrm{E}\right)$ and

137 covers an area of approximately $14,600 \mathrm{~km}^{2}$. The study area $\left(\approx 1,500 \mathrm{~km}^{2}\right)$ is located in the 138 northern part of HNP, in the Main Camp area (Appendix S1: Fig. S1), and is characterized by

139 Kalahari sandy soils. The vegetation is primarily bushed woodland and bushland savanna,

140 interspersed with small patches of grassland (Arraut et al. 2018). HNP is semi-arid (mean 141 annual rainfall=600 $\mathrm{mm}$, coefficient of variation=25\%) with a wet season from November to 142 April and a dry season from May to October (Chamaillé-Jammes et al. 2006). Availability of 143 surface water is primarily from rainwater collected in natural depressions. However, most of 144 these natural depressions do not hold water during the dry season, when water is artificially 145 pumped in about 50 waterholes spread throughout HNP (Appendix S1: Fig. S1). Hyaena 146 density in the study area is 11.0 hyaenas $/ 100 \mathrm{~km}^{2}$ (Unpubl. data) and lion density is 4.3

147 lions $/ 100 \mathrm{~km}^{2}$ (Loveridge et al. 2016). Wild dogs (Lycaon pictus), cheetahs (Acinonyx jubatus) 148 and leopards (P. pardus) are also present in the study area but less abundant.

\section{Predator GPS data}

151 From July 2009 to October 2013, nine adult hyaenas (eight females and one male) belonging to 152 four different clans were equipped with GPS collars (see Périquet 2014 for details). Hyaenas 
153 spent most of their time foraging alone (Périquet et al. 2015b) and their fission-fusion

154 dynamics precluded from assessing group sizes during interactions. During the same period, 27 155 adult lions (20 males and 7 females) were also equipped with GPS collars (see Benhamou et al.

1562014 for details). At least one male lion per coalition and one female lion per pride were 157 collared. As lionesses from the same pride and males from the same coalition spend most of 158 their time together in the study area (Valeix et al. 2009), we assumed that individual locations 159 generally represent those of their pride and coalition. Relevant animal care protocols were

160 followed during capture and collaring of carnivores (Wildlife Drugs Sub-committee of the 161 Drugs Control Council of Zimbabwe and Zimbabwe Veterinary Association, Wildlife Group, 162 and licenses to acquire, possess and administer game capture drugs/dangerous drugs), and 163 permissions were provided by the appropriate agencies (Research Council of Zimbabwe,

164 Zimbabwe Parks and Wildlife Management Authority). All applicable institutional and/or 165 national guidelines for the care and use of animals were followed. Collars were programmed to 166 take hourly fixes during the night (between $6 \mathrm{pm}$ and $6 \mathrm{am}$ ). Lion collars were not set up to record GPS locations at the same time as hyaena collars and the frequency of locations varied

168 from one location every hour to one location every $2 \mathrm{~h}$ at night (12 individuals with a collar set 169 up to record a GPS location every $2 \mathrm{~h}$ ).

170 A prerequisite for two animals to encounter each other is that their space use overlaps. We 171 preliminarily quantified the static interactions between hyaenas and lions using home range 172 overlap metrics. Using a 2D measure of home range overlap, we found that on average $97.9 \pm$ $1730.5 \%($ range $=85.4-100 \%)$ of a given hyaena home range was overlapping with at least one 174 lion home range (see Appendix S2 for details).

\section{Proximity index and encounter definition}

177 Proximal fixes were used to identify and define the encounters between hyaenas and lions. We 178 defined proximal fixes as simultaneous hyaena and lion GPS locations within $200 \mathrm{~m}$ of each 
179 other. This threshold is conservative compared to other studies (500m in Broekhuis et al. 2019

180 or Courbin et al. 2016; 800m in Jordan et al. 2017) as we wanted to be sure that both species

181 were aware of each other's presence. For each hyaena-lion pair with overlapping home ranges,

182 we computed the proximity index as the proportion of the number of proximal fixes over the 183 total number of simultaneous fixes for the pair (Long et al. 2014). This proximity index is a

184 measure of how often hyaenas encounter lions in the landscape. In order to quantify if hyaena

185 and lions encountered each other more often than expected by chance, we generated proximity

186 indices by randomly creating new GPS locations for hyaenas but keeping the lion locations

187 unchanged. These random locations were generated in a similar way as in a Step Selection

188 Function framework (Fortin et al. 2005). Each hyaena used location was set as the starting

189 point from which we created 100 steps (a step is the straight line movement between two

190 successive GPS locations) by randomly drawing step length and turning angle from their

191 respective empirical distributions obtained by pooling step data from all other hyaenas, as

192 recommended by Fortin et al. (2005). In case of a hyaena GPS location falling within $200 \mathrm{~m}$ of 193 several lion GPS locations, we used the distance to the closest lion location.

194 Movement of the given hyaena-lion pair during each night containing at least one pair of 195 proximal fixes was plotted and visually examined. We categorized whether an encounter 196 occurred at a large prey carcass (> $120 \mathrm{~kg}$ ) that could provide scavenging opportunities. We 197 thus defined encounters occurring in the presence of a carcass when proximal fixes were 198 located near a known carcass (found in the field during systematic hyaena GPS cluster searches 199 or opportunistically) or near a large and clearly defined lion cluster ( $>5 \mathrm{~h}$ within a $200 \mathrm{~m}$ 200 radius). Previous work using GPS clusters to investigate potential lion kill sites used cluster of $201 \geq 2$ GPS locations within 100m of each other (e.g. Tambling and Belton 2009; Tambling et al. 202 2012; Davidson et al. 2013), but since we did not investigate these clusters in the field and 203 lions hardly ever rest for more than $5 \mathrm{~h}$ in the same location at night (Schaller 1972) we feel 204 confident that clusters identified using our definition represent carcasses. When there was no 8 
clear GPS cluster near the proximal fixes, we assumed that the encounter occurred in the absence of a carcass. While we acknowledge that with this classification, small carcasses

207 would be missed, these are unlikely to provide scavenging opportunities. In the presence of 208 small and loose clusters (multiple GPS locations not tightly grouped together and scattered

209 within a radius of $\sim 100 \mathrm{~m}$ ), we classified the encounter as undefined in terms of carcass

210 presence. Depending on the situation, multiple pairs of proximal fixes could be assigned to the

211 same encounter (for instance, proximal fixes occurring in the vicinity of a given carcass).

\section{$213 \quad$ Encounter characteristics}

214 Seasonality - Each encounter was attributed to the wet or dry season based on the date when it

215 occurred. We used a $\mathrm{Chi}^{2}$ test to test for the effects of the presence of a carcass on the

216 seasonality of encounters.

217 Distance to water - Because waterholes play an important role in the spatial ecology of both

218 lions (Valeix et al. 2010) and hyaenas (Périquet 2014) in HNP, we computed the distance

219 between the first proximal fixes and the nearest pumped waterhole (distance to water hereafter)

220 for each encounter. We tested the effect of distance to water on the probability of encounter

221 using Generalized Linear Models (GLMs) with a binomial error structure with encounter

222 (coded 0/1) as a the dependent variable and distance to water as an explanatory variable. We

223 used separated models for encounter in the presence and absence of a carcass, irrespective of

224 the season. For each model, 500 locations with no encounter were drawn randomly from the

225 hyaena GPS dataset only including nights during which no encounter between hyaenas and

226 lions was identified.

227 Duration - The duration of an encounter in the presence of a carcass was defined as the time

228 elapsed between the first and the last proximal fixes still associated with the given carcass

$229(\leq 200 \mathrm{~m})$, even if they were separated by several hours and interspersed with some non-

230 proximal fixes (it is indeed common for carnivores to visit a carcass over several consecutive 
231 days, Cozzi et al. 2015). We extracted the GPS data of the two species from the night of the

232 first proximal fixes to the night of the last proximal fixes for subsequent analyses. The duration

233 of an encounter in the absence of a carcass was calculated from the first to the last pair of

234 consecutive proximal fixes. Since all encounters away from carcasses were restricted to one

235 night, we extracted the GPS data of the two species for the night when the encounter occurred

236 for subsequent analyses. Because of high heterogeneity in the duration between encounter in

237 the presence and absence of a carcass, we used a Wilcoxon rank sum test to determine the

238 effect of carcass presence on encounter duration.

$240 \quad$ Which species provoked the encounter?

241 For all encounters (presence and absence of a carcass), we computed the speed (in $\mathrm{m} / \mathrm{h}$ ) of

242 movement during the hour preceding the start of the encounter for both species. Speed was

243 only computed if the last GPS location was taken a maximum of $2 \mathrm{~h}$ before the start of the

244 encounter.

245 For encounters in the presence of a carcass, we further performed a visual examination of the

246 movement of the two species before the start of the encounter (GPS locations preceding the

247 first pair of proximal fixes but belonging to the same night) to identify which species was the

248 first at the carcass $(\leq 200 \mathrm{~m})$. It is noteworthy that the species arriving first at a carcass did not

249 necessarily kill the prey. For encounters in the absence of a carcass, we also visually examined

250 the movement of each species before the encounter and defined two situations: (1) one species

251 was in the vicinity $(\leq 200 \mathrm{~m})$ of the encounter location while the other one moved towards the

252 encounter location, in which case the species moving towards the encounter location was

253 considered as attracted to the location of the other species, or (2) both species showed clear

254 movement before the encounter. In this case, we calculated, for each species, an attraction

255 score for each step of the 4 hours preceding the encounter. 
256 The attraction score was based on the direction of the step compared to the simultaneous step 257 made by the other species (see Fig. 1a for details). The attraction score for a step could take 5

258 values: +1 if the step of species A was directed toward the step of species $B \pm 10^{\circ}$ (case of

259 "strong attraction"); +0.5 if the step of species A was directed toward the step of species

$260 \mathrm{~B} \pm 30^{\circ}$ - but excluding cases of strong attraction - (case of "mild attraction"); -1 when the step

261 of species A was directed opposite the step of species B $\left( \pm 10^{\circ}\right)$ (case of "strong avoidance"); -

2620.5 when the step of species A was directed opposite the step of species B $\pm 30^{\circ}$ - but

263 excluding cases of strong avoidance - (case of "mild avoidance"); and 0 in any other case

264 ("independent movement"). Finally, we summed the scores of the steps of the 4 hours

265 preceding the encounter to calculate an overall attraction score for each species (see Fig. $1 \mathrm{~b}$ for

266 an example). Based on these overall scores, we established if one species was clearly attracted

267 to the location of the other species and therefore likely to provoke the encounter (positive

268 overall score while the other species had a null or negative overall score) or avoiding the

269 location of the other species (negative overall score while the other species had a null or

270 positive overall score). Only GPS locations separated by a maximum of $2 \mathrm{~h}$ and only

271 encounters before which at least two steps could be computed were taken into account. In

272 addition, to be sure that hyaenas and lions could have detected each other's presence, we only

273 considered steps for which both starting and ending points were located within $2 \mathrm{~km}$ of the

274 other species.

\section{Which species was dominant over the encounter?}

277 For encounters in the presence of a carcass, if the species present at the carcass moved away

278 (further than $200 \mathrm{~m}$ from the carcass) in the 2 hours following the arrival of the second species,

279 the latter was considered dominant. However, if the species at the carcass was not displaced,

280 and the arriving species spent less than $2 \mathrm{~h}$ in the vicinity of the carcass $(\leq 200 \mathrm{~m})$ before

281 moving away (even if it came back to the carcass at a later stage during the encounter), the 
282 former was considered as dominant. Staying at the carcass after the end of the encounter (if the

283 first arriving species was not displaced) was not considered as an indication of dominance.

284 Indeed, while a carcass can initially provide a lot of food (assuming it was killed or discovered 285 in good condition), its profitability decreases with time. Thus, a species leaving the carcass 286 might do so when it is not profitable enough to stay longer. For each encounter, we established

287 whether at least one adult male lion was present as the presence of a male lion has often been

288 reported as the determinant of the outcome of aggressive interactions between lions and

289 hyaenas (Cooper 1991; Höner et al. 2002). At the time of the study, all male coalitions had at 290 least one individual collared in the study area. We further computed the speed of movement 291 during the hour following the end of the encounter for both species. Speed was only computed

292 if the first GPS location was taken maximum $2 \mathrm{~h}$ after the end of the encounter.

293 To test for differences in speed and distance to the carcass between the two species, we used

294 linear mixed effect models including speed or distance to the carcass as the dependent variable, 295 species as the explanatory variable, and carcass identity as a random intercept. Both speed and 296 distance to carcass were log transformed to meet normality assumptions.

297 For encounters in the absence of a carcass, we used the attraction score approach described 298 above for the $4 \mathrm{~h}$ following the end of the encounter, to assess which species avoided the other 299 one after the encounter. When there were insufficient data to characterize the movement of the 300 two species for $4 \mathrm{~h}$ after an encounter, we used speed during the hour immediately following 301 the encounter to determine if one species was clearly moving away from the other one. In this 302 case, we considered a ratio of hyaena speed to lion speed above 2 to be indicative of a 303 behaviour of lion avoidance by hyaenas and of less than 0.5 to be indicative of a behaviour of 304 hyaena avoidance by lions.

305 We tested for a significant difference in the speed at which lions and hyaenas moved before 306 and after an encounter depending on the presence of a carcass using a linear model including 
the interaction between species and carcass presence (coded as 0/1) as explanatory variables and speed as dependent variable. Speed was log transformed to meet the model assumptions.

310 All data extraction and analyses were conducted using the R software (R Core Team 2020,

311 version 3.5.2) with the packages adehabitaHR (version 0.4.15), adehabitatLT (version 0.3.23,

312 Calenge 2006), lmer (version 3.0-1, Bates 2010). Values are provided as the mean \pm standard

313 error (SE) unless mentioned otherwise.

\section{RESULTS}

\section{Proximity index and encounter definition}

317 Proximity index - We found a total of 108 proximal fixes out of 170,120 simultaneous fixes in 318 our dataset, which resulted in an average proximity index for a given hyaena of $0.0011 \pm$ 3190.0023 (range $=0-0.0107, \mathrm{n}=90)$. The average of the randomly generated proximity index was 320 lower $(0.0005 \pm 0.00001$, range $=0-0.0076$, Fig. 2$)$ suggesting that hyaenas and lions came into 321 contact more often than expected by chance.

322 Encounter definition - Based on visual examination of hyaena and lion movements around 323 proximal fixes, we defined 70 encounters between the two predators. Twenty-eight of them 324 occurred in the presence of a carcass and 35 occurred in the absence of a carcass. For seven 325 encounters, the presence or absence of a carcass could not be established with certainty and 326 their characteristics are not discussed hereafter (see Appendix S3 for a complete list of 327 encounters and their characteristics).

\section{Encounter characteristics}

330 Seasonality - More than half of the encounters in the presence of a carcass occurred during the 331 wet season $(57.1 \%, \mathrm{n}=12$; Fig. 3a, Appendix S3). Most encounters in the absence of a carcass 332 occurred during the dry season $(77.1 \%$, n=27; Fig. 3a, Appendix S3). Encounters in the 
333 presence of a carcass were significantly more likely to occur during the wet season $\left(\chi^{2}=6.4\right.$,

$334 \mathrm{p}=0.01)$.

335 Distance to water - In the presence of a carcass, we found no effect of the distance to water on

336 the probability of encounter $(\mathrm{p}=0.64)$, suggesting that these were evenly distributed in the

337 landscape. However, encounters in the absence of a carcass were more likely to occur as the

338 distance to water decreased ( $\mathrm{z}$ value $=-0.36, \mathrm{p}=0.0003)$, see distribution of the encounters

339 depending on the distance to water in Fig. 3b).

340 Duration - Excluding the six encounters characterized by one pair of proximal fixes only (i.e.

341 for which we could not estimate duration), encounters in the presence of a carcass lasted on

342 average $40 \pm 9 \mathrm{~h}$ ranging from 1 to $162 \mathrm{~h}$ (nearly seven days, Fig. 3c, see also Appendix S4: Fig.

343 S2 for examples of encounters). For encounters in the absence of a carcass, $80 \%$ of the 35

344 encounters were characterized by only one pair of proximal fixes (Fig. 3c, see also Appendix

345 S4: Fig. S4 for examples of encounters) and they were significantly shorter than encounters in

346 the presence of a carcass $(1.4 \pm 0.2 \mathrm{~h}$, range: $1-6 \mathrm{~h}, \mathrm{~W}=2088, \mathrm{p}=0.004)$.

\section{Which species provoked the encounter?}

349 Encounters in the presence of a carcass - Of the 28 encounters at a carcass, lions were the first

350 at the carcass in $71 \%$ of the cases $(n=20$, Fig. 4$)$. The few cases $(n=7)$ when hyaenas arrived

351 first corresponded to situations with only lionesses present. In the hour preceding the

352 encounter, hyaenas moved significantly faster $(1,011 \pm 230 \mathrm{~m} / \mathrm{h}, \mathrm{n}=27)$ than lions $(580 \pm 200 \mathrm{~m} / \mathrm{h}$, $353 \mathrm{n}=27, \mathrm{t}=3.12, \mathrm{p}=0.002$, Appendix S4: Fig. S1).

354 Encounters in the absence of a carcass - A male lion was present in $34 \%(n=12)$ of the 355 encounter in the absence of a carcass. When movement could be characterized before the 356 encounter $(n=26)$, hyaenas appeared to be attracted to lions ( $42 \%$ of the encounters) or to 357 ignore them, but they never seemed to avoid them (Fig. 4, Appendix S3: Table S2). In contrast, 358 lions showed movement characteristics of avoidance before the encounter in $11.5 \%$ of 14 
encounters (Fig 4, Appendix S3: Table S2) and of attraction in 15\% of encounters. In the hour

360 preceding the encounter, hyaenas moved on averaged at $1,045 \pm 195 \mathrm{~m} / \mathrm{h}(\mathrm{n}=34)$, which was not

361 significantly different from the lion speed of $766 \pm 136 \mathrm{~m} / \mathrm{h}(\mathrm{n}=31, \mathrm{t}=0.47, \mathrm{p}=0.64$, Appendix

362 S4: Fig S3).

\section{Which species was dominant over the encounter?}

365 Encounters in the presence of a carcass - We found that lions were dominant over access to the

366 carcass in 18 out of the 20 encounters where dominance could be clearly established (Fig. 4,

367 Appendix S3: Table S1, see Appendix S4: Fig. S2 for examples of encounters). Hyaenas were

368 dominant only once. During the 22 encounters that were characterized by more than one pair of

369 proximal fixes, hyaenas moved on average $739 \pm 47 \mathrm{~m} / \mathrm{h}$ (range $=1-5,600 \mathrm{~m} / \mathrm{h}, \mathrm{n}=479$ steps)

370 which was significantly more than lions $(115 \pm 13 \mathrm{~m} / \mathrm{h}$, range $=0-1900 \mathrm{~m} / \mathrm{h}, \mathrm{n}=409$ steps, $\mathrm{t}=15.98$,

$371 \mathrm{p}<0.0001)$. Hyaenas were also found significantly further away from the carcass than lions

372 (hyaena: $1,614 \mathrm{~m} \pm 127 \mathrm{~m}$, range $=4-15,400 \mathrm{~m}, \mathrm{n}=544$ locations; lion: $250 \pm 2 \mathrm{~m}$, range $=0-1,900 \mathrm{~m}$,

$373 \mathrm{n}=483$ locations; $\mathrm{t}=20.48, \mathrm{p}<0.0001)$. In the hour following the end of the encounter, hyaenas

374 moved at $527 \pm 129 \mathrm{~m} / \mathrm{h}(\mathrm{n}=28)$, which was significantly more than lions $(60 \pm 32 \mathrm{~m} / \mathrm{h}, \mathrm{n}=27$,

$375 \mathrm{t}=5.49, \mathrm{p}<0.0001$, Appendix S4: Fig. S1).

376 Encounters in the absence of a carcass - When movement could be characterized after the

377 encounter ( $n=33)$, hyaenas seemed to move away from lions in only $18 \%$ of the cases (Fig. 4,

378 Appendix S3: Table S2), whereas lions moved away from hyaenas in 58\% of the cases (Fig. 4,

379 Appendix S3: Table S2). In the hour following the end of the encounter, hyaenas moved at

$380578 \pm 146 \mathrm{~m} / \mathrm{h}(\mathrm{n}=33)$ and lions at $658 \pm 118 \mathrm{~m} / \mathrm{h}(\mathrm{n}=30$, Fig. S3) and the difference was not

381 significant $(\mathrm{t}=1.07, \mathrm{p}=0.28)$. After an encounter, we found a significant effect of the interaction

382 between species and the presence of a carcass $(\mathrm{F}=14.48, \mathrm{p}=0.002)$ with lions moving faster in

383 the absence of a carcass compared to when a carcass was present $(t=6.73, p<0.0001)$. We found 
no effect of the presence of a carcass on hyaena movement speed after an encounter $(\mathrm{t}=0.11$, p=0.90, Appendix S4: Fig. S1 and S3).

\section{DisCUSSION}

388 The analysis of simultaneous GPS locations of hyaenas and lions showed that these two apex

389 predator species did not avoid encountering each other. Rather, they encountered each other

390 more often than expected by chance. Encounters between lions and hyaenas may occur through

391 either active mechanisms of attraction between the two predators or passive mechanisms

392 whereby the two predators are attracted to the same locations in the landscape.

\section{Wet season: time for intraguild facilitation}

395 During the wet season, lions and hyaenas encountered each other mainly at carcasses and

396 throughout the landscape (i.e. independently of water sources). As we expected, hyaenas

397 arrived at carcasses after the lions, and travelled far and fast to reach the carcasses. Lions

398 killing prey and feeding on a carcass are indeed likely to be heard (noises of high-speed chase,

399 struggle, and prey distress call) and smelt (blood and stomach content odour) by hyaenas from

400 quite a distance, and hyaena intraspecific communication may also play a role resulting in

401 hyaena moving up to $5 \mathrm{~km}$ in the hour preceding its arrival to a carcass that had just been killed

402 by lions. Further, lions were dominant over the access to carcasses, and hyaenas did not stay 403 near the carcasses while the lions were present (Appendix S5). However, hyaenas came back 404 regularly to the carcasses for up to one week after their first arrival. This suggests that hyaenas 405 regularly checked whether lions were still at the carcass and fed on the carcass only after the 406 lions had gone. Hyaenas are particularly well-equipped to make use of carcass parts usually 407 disregarded by other species (Kruuk 1972), and are therefore able to benefit from whatever was 408 left by lions. Our results showed that hyaenas hardly ever displaced lions from a carcass. This 409 is consistent with result from an experiment conducted in South Africa showing that 16 
410 interactions occur at large carcasses over which lions maintain preferential access (Amorós et

411 al. 2020). Previous studies showed that the likelihood of hyaenas wining an encounter with

412 lions depends on the group sizes of the two species (with hyaenas likely to take over a kill

413 when they outnumber lions by a factor of 4 -Cooper 1991) and the presence of an adult male

414 lion (Kruuk 1972; Cooper 1991; Trinkel and Kastberger 2005). We do not know the number of

415 hyaenas and lions involved in the encounters mentioned in this study. However, male lions

416 were present during most of these interactions. As the population of adult male lions increased

417 after a moratorium on trophy hunting around HNP in 2005-2008 (Loveridge et al. 2016), male

418 lions are now more likely to be present and thus hyaenas less likely to win their encounters

419 with lions. In our study, even though we cannot infer if the prey was killed or found dead by

420 lions, we suggest that lions producing/finding a carcass provide extra scavenging opportunities

421 for hyaenas by making the given carcass more easily located.

422 Carcasses are widely used resources across ecosystems, which have been overlooked for

423 terrestrial mammals, and their ecological importance, along with that of scavenging, has

424 recently gained increased recognition in community ecology (Wilson \& Wolkovich 2011,

425 Pereira et al. 2014). For instance, wolverine (Gulo gulo) take advantage of prey killed by wolf

426 (Canis lupus) and lynx (Lynx lynx, van Dijk et al. 2008) and access to these carcasses,

427 especially during winter, has a stabilizing effect on wolverine populations as well as on the

428 whole food web (Wilson and Wolkovich 2011). Altogether, our results illustrate that intra-

429 guild facilitation (through scavenging opportunities) may be an important process to explain

430 the coexistence between lions and hyaenas. As expected based on the hunting mode of

431 hyaenas, our results further suggest that hyaena scavenging from lion kills mainly occurs in the

432 wet season. Seasonal variations in the prevalence of scavenging have already been highlighted

433 Pereira et al. (2014).

$435 \quad$ Dry season: time for interference competition? 
436 We revealed a significant number of encounters between lions and hyaenas in the dry season.

437 They encountered each other mainly in the absence of a carcass. In the dry season, hyaenas are

438 likely to be more efficient killers than during the wet season and more carcasses from

439 herbivore natural mortality are likely to be available in the landscape, which will increase the

440 chance of locating a carcass from which lions are absent. Altogether, this may explain the

441 lower number of interactions at carcasses between hyaenas and lions in the dry season.

442 Interestingly, during the dry season, lions and hyaenas encountered each other mainly close to

443 waterholes.

444 In arid and semi-arid savannas, large herbivores tend to aggregate around scarce water sources

445 in the dry season (Thrash et al. 1995; Redfern et al. 2003). This is the case in HNP (Valeix et

446 al. 2009; Valeix 2011) where waterholes can be considered as prey hotspots during the dry

447 season. Both predators are attracted to these areas (Valeix et al. 2010; Périquet 2014), and are

448 therefore more likely to encounter each other there. Our results suggest that management

449 decisions to artificially provide water throughout the year may influence apex predator

450 interactions by creating, maintaining and strengthening prey hotspots.

451 Encounters in the absence of a carcass were very short and usually limited to a single contact

452 point with one or both species moving away immediately afterwards. This suggests that in the

453 absence of food, predators avoid spending time near each other. Hyaenas did not avoid these

454 encounters, and even appeared to provoke many of them. Surprisingly, lions seemed to avoid

455 the encounter on a few occasions. Additionally, hyaenas did not appear to flee after an

456 encounter, while lions quickly moved away on more than half of the encounters. Altogether,

457 these results are quite counterintuitive and suggest that hyaenas were not scared of proximity to

458 lions and were even attracted to them. These observations could result from hyaenas following

459 lions to assess kleptoparatism and scavenging opportunities, as foxes have been observed to

460 follow striped hyaenas (Hyena hyena, Macdonald 1978). Yet, we found that hyaenas hardly

461 ever displace lions from carcasses and that very few encounters at carcasses occur in the dry 18 
season, making this scenario unlikely. The observed patterns could result from two scenarios: a

463 passive interference scenario whereby the two predators actively select for areas rich in prey

464 and lions leave a patch due to prey disturbance following hyaena arrival, or an active

465 interference scenario whereby hyaenas actively seek to encounter lions near waterholes to

466 displace them from these prime hunting grounds. In the two scenarios, our results would

467 suggest an interference competition between the two species, with potential negative effects

468 from hyaenas on lions, which would challenge the widely accepted view that lions are

469 dominant over hyaenas. While many studies (including this one) found lions to be dominant

470 over hyaenas in terms of food access (Cooper 1991; Höner et al. 2002; Trinkel and Kastberger

471 2005), to our knowledge, this is the first time that interactions between the two species away

472 from food resources are studied.

Limits and future directions

475 Our results show the great potential of GPS data loggers to provide extensive information on 476 interactions between species. It is however important to note that the frequency of encounters

477 was underestimated as the proximity index was calculated from GPS locations separated by 478 one hour at least, and short encounters that occurred between consecutive $1 \mathrm{~h}$ locations may 479 have been undetected. Additionally, we could not quantify the encounters involving a collared 480 animal and a non-collared one. Significant improvements in battery life should soon allow the 481 use of this technology with high frequency of GPS fixes acquisition that would provide a much 482 finer spatiotemporal scale to study interactions between apex predators. This would allow 483 testing the scenarios sketched above about the underlying mechanisms of the interactions. We 484 also encourage the development of methods to quantify attraction and avoidance from 485 simultaneous movement data (as started by Jordan et al. 2017 and Chisholm et al. 2019). 486 Additionally, only one individual (at best two) per predator group was radio-collared, and since 487 hyaena groups are characterized by a highly dynamic fission-fusion (Kruuk 1972; Smith et al. 19 
2008), we cannot say with certainty whether some hyaenas arrived before or stayed after the

489 collared one. Hyaenas also behave differently depending on their social rank (Smith et al.

490 2008) and they have marked personality which could influence the outcome of interactions

491 with lions (Watts et al. 2010).

\section{Conclusion}

494 While interference competition occurs between lions and hyaenas, as it is widely accepted

495 between apex predators (e.g. Broekhuis et al. 2013; Vanak et al. 2013; du Preez et al. 2015),

496 the extent of facilitation through scavenging opportunities should not be ignored (van Dijk et

497 al. 2008; Mattisson et al. 2011; Pereira et al. 2014; Sivy et al. 2017). Our results show that the

498 balance between intraguild competition and facilitation is likely to be affected by

499 environmental conditions and at least in semi-arid savanna ecosystems is most probably driven

500 by water availability and seasonality.

\section{ACKNOWLEDGEMENTS}

503 The Zimbabwe Research Council and the Zimbabwe Parks and Wildlife Management

504 Authority are kindly acknowledged for providing the opportunity to carry out this research. We

505 deeply thank Nicholas Elliot, Jane Hunt and Brent Stapelkamp for the collection of lion GPS

506 data. This study was supported by the HERD project (Hwange Environmental Research

507 Development), funded by the ANR FEAR (ANR-08-BLAN-0022), the CNRS, the RP-PCP

508 platform and by the Hwange Lion Project supported by grants from The Darwin Initiative for

509 Biodiversity Grant 162/09/015, The Eppley Foundation, Disney Foundation, Marwell

510 Preservation Trust, Regina B. Frankenburg Foundation, The Rufford Maurice Laing

511 Foundation, Panthera Foundation, and the generosity of Joan and Riv Winant. SP salary was

512 provided by the ENS of Lyon and UCBL Lyon1. ER was supported by the Spanish Ministry of

513 Science and Innovation co-funded by FEDER (projects CGL2009-07301/BOS, CGL2012- 252 

of the CC LBBE/PRABI. This work benefited from ideas developed in the framework of the ANR project FUTURE-PRED (ANR-18-CE02-0005-01). We thank two anonymous reviewers

517 for their helpful comments on a previous version of the manuscript.

\section{REFERENCES}

Amorós M, Gil-Sánchez JM, de las N López-Pastor B, Moleón M (2020) Hyaenas and lions: how the largest African carnivores interact at carcasses. Oikos 1-36. https://doi.org/10.1111/oik.06846

Arraut EM, Loveridge AJ, Chamaillé-Jammes S, et al (2018) The 2013-2014 vegetation structure map of Hwange National Park, Zimbabwe, produced using free satellite images and software. Koedoe 60:a1497. https://doi.org/10.4102/koedoe.v60i1.1497

Bates DM (2010) lme4: Mixed-effects modeling with R

Benhamou S, Valeix M, Chamaillé-Jammes S, et al (2014) Movement-based analysis of interactions in African lions. Anim Behav 90:171-180

Broekhuis F, Cozzi G, Valeix M, et al (2013) Risk avoidance in sympatric large carnivores: reactive or predictive? J Anim Ecol 82:1098-1105

Broekhuis F, Madsen EK, Keiwua K, Macdonald DW (2019) Using GPS collars to investigate the frequency and behavioural outcomes of intraspecific interactions among carnivores: A case study of male cheetahs in the Maasai Mara, Kenya. PLoS ONE 14:e021391016. https://doi.org/10.1371/journal.pone.0213910

Bruno JF, Stachowicz JJ, Bertness MD (2003) Inclusion of facilitation into ecological theory. Trends Ecol Evol 18:119-125

Calenge C (2006) The package "adehabitat" for the R software: A tool for the analysis of space and habitat use by animals. Ecological Modelling 197:516-519. https://doi.org/10.1016/j.ecolmodel.2006.03.017

Chamaillé-Jammes S, Fritz H, Murindagomo F (2006) Spatial patterns of the NDVI-rainfall relationship at the seasonal and interannual time scales in an African savanna. International Journal of Remote Sensing 27:5185-5200 
Chapron G, Kaczensky P, Linnell JD, et al (2014) Recovery of large carnivores in Europe's modern human-dominated landscapes. Science 346:1514-1517. https://doi.org/10.1126/science.1256620

Chisholm S, Stein AB, Jordan NR, et al (2019) Parsimonious test of dynamic interaction. Ecol Evol 90:171-11. https://doi.org/10.1002/ece3.4805

Cooper SM (1991) Optimal hunting group size: the need for lions to defend their kills against loss to spotted hyaenas. African Journal of Ecology 29:130-136

Courbin N, Fortin D, Dussault C, et al (2013) Multi-trophic resource selection function enlightens the behavioural game between wolves and their prey. J Anim Ecol 82:10621071. https://doi.org/10.1111/1365-2656.12093

Courbin N, Loveridge AJ, Macdonald DW, et al (2016) Reactive responses of zebras to lion encounters shape their predator-prey space game at large scale. Oikos 125:829-838. https://doi.org/10.1111/oik.02555

Cozzi G, Börger L, Hutter P, et al (2015) Effects of Trophy Hunting Leftovers on the Ranging Behaviour of Large Carnivores: A Case Study on Spotted Hyenas. PLoS ONE 10:e0121471

Cozzi G, Broekhuis F, McNutt JW, et al (2012) Fear of the dark or dinner by moonlight? Reduced temporal partitioning among Africa's large carnivores. Ecology 93:2590-2599

Davidson Z, Valeix M, Van Kesteren F, et al (2013) Seasonal Diet and Prey Preference of the African Lion in a Waterhole-Driven Semi-Arid Savanna. PLoS ONE 8:e55182. https://doi.org/10.1371/journal.pone.0055182.t003

du Preez B, Hart T, Loveridge AJ, Macdonald DW (2015) Impact of risk on animal behaviour and habitat transition probabilities. Animal Behaviour 100:22-37. https://doi.org/10.1016/j.anbehav.2014.10.025

Durant SM (2000) Living with the enemy: avoidance of hyenas and lions by cheetahs in the Serengeti. Behavioral Ecology 11:624-632. https://doi.org/10.1093/beheco/11.6.624

Fortin D, Beyer HL, Boyce MS, et al (2005) Wolves influence elk movements: behavior shapes a trophic cascade in Yellowstone National Park. Ecology 86:1320-1330

Höner OP, Wachter B, East ML, Hofer H (2002) The response of spotted hyaenas to long-term changes in prey populations: functional response and interspecific kleptoparasitism. Journal of Animal Ecology 71:236-246. https://doi.org/10.1046/j.13652656.2002.00596.x

Jordan NR, Buse C, Wilson AM, et al (2017) Dynamics of direct inter-pack encounters in endangered African wild dogs. Behav Ecol Sociobiol 71:1-12. https://doi.org/10.1007/s00265-017-2338-9

Kohl MT, Ruth T, Metz MC, et al (2019) Do prey select for vacant hunting domains to minimize a multi-predator threat? Ecol Lett 73:876-10. https://doi.org/10.1111/ele.13319 
Krofel M, Kos I, Jerina K (2012) The noble cats and the big bad scavengers: effects of dominant scavengers on solitary predators. Behav Ecol Sociobiol 66:1297-1304. https://doi.org/10.1007/s00265-012-1384-6

Kruuk H (1972) The Spotted Hyena: A Study of Predation and Social Behavior. University of Chicago Press, Chicago

Linnell JD, Strand O (2000) Interference interactions, co-existence and conservation of mammalian carnivores. Div Distrib 6:169-176

Long JA, Nelson TA, Webb SL, Gee KL (2014) A critical examination of indices of dynamic interaction for wildlife telemetry studies. J Anim Ecol 83:1216-1233. https://doi.org/10.1111/1365-2656.12198

Loveridge AJ, Valeix M, Chapron G, et al (2016) Conservation of large predator populations: Demographic and spatial responses of African lions to the intensity of trophy hunting. Biol Conserv 204:247-254. https://doi.org/10.1016/j.biocon.2016.10.024

Macdonald DW (1978) Observations on the behaviour and ecology of the striped hyena, Hyena hyena in Israel. Israel Journal of Zoology 27:189-198

Mattisson J, Andrén H, Persson J, Segerström P (2011) Influence of intraguild interactions on resource use by wolverines and Eurasian lynx. J Mamm 92:1321-1330. https://doi.org/10.1644/11-MAMM-A-099.1

Miller JRB, Pitman RT, Mann GKH, et al (2018) Lions and leopards coexist without spatial, temporal or demographic effects of interspecific competition. J Appl Ecol 87:17091726. https://doi.org/10.1111/1365-2656.12883

Mills MGL (1990) Kalahari hyaenas: Comparative behavioural ecology of two species. The Blackburn Press, Caldwell NJ, USA

Owen-Smith RN (2002) Adaptive Herbivore Ecology. Cambridge University Press, Cambridge

Palmer MS, Fieberg J, Swanson A, et al (2017) A 'dynamic' landscape of fear: prey responses to spatiotemporal variations in predation risk across the lunar cycle. Ecol Lett 20:13641373. https://doi.org/10.1111/ele.12832

Palomares F, Caro TM (1999) Interspecific killing among mammalian carnivores. The American Naturalist 153:492-508

Pereira LM, Owen-Smith N, Moleón M (2014) Facultative predation and scavenging by mammalian carnivores: seasonal, regional and intra-guild comparisons. Mammal Rev 44:44-55. https://doi.org/10.1111/mam.12005

Périquet S (2014) Sharing the top: How do Spotted hyaenas cope with Lions? Apex predator coexistence in a wooded savanna. PhD, Université Claude Bernard, Lyon 1

Périquet S, Fritz H, Revilla E (2015a) The Lion King and the Hyaena Queen: large carnivore interactions and coexistence. Biol Rev 90:1197-1214. https://doi.org/10.1111/brv.12152 
Périquet S, Valeix M, Claypole J, et al (2015b) Spotted hyaenas switch their foraging strategy as a response to changes in intraguild interactions with lions. J Zool 297:245-254. https://doi.org/10.1111/jzo.12275

R Core Team (2020) R: A language and environment for statistical computing. R Foundation for Statistical Computing. Version 4.0.2. Vienna, Austria

Rasphone A, Kamler JF, Macdonald DW (2020) Temporal partitioning by felids, dholes and their potential prey in northern Laos. Mamm Res 40:36-11. https://doi.org/10.1007/s13364-020-00524-9

Redfern JV, Grant R, Biggs HC, Getz WM (2003) Surface-water constraints on herbivore foraging in the Kruger National Park, South Africa. Ecology 84:2092-2107. https://doi.org/10.1890/01-0625

Ripple WJ, Estes JA, Beschta RL, et al (2014) Status and Ecological Effects of the World's Largest Carnivores. Science 343:1241484-1241484. https://doi.org/10.1126/science.1241484

Ritchie EG, Johnson CN (2009) Predator interactions, mesopredator release and biodiversity conservation. Ecology Letters 12:982-998. https://doi.org/10.1111/j.14610248.2009.01347.x

Schaller GB (1972) The Serengeti lion- A Study of Predator-Prey Relations. University of Chicago Press, Chicago

Schuette P, Wagner AP, Wagner ME, Creel S (2013) Occupancy patterns and niche partitioning within a diverse carnivore community exposed to anthropogenic pressures. Biol Conserv 158:301-312. https://doi.org/10.1016/j.biocon.2012.08.008

Sivy KJ, Pozzanghera CB, Grace JB, Prugh LR (2017) Fatal Attraction? Intraguild Facilitation and Suppression among Predators. Am Nat 190:663-679. https://doi.org/10.5061/dryad.tj590

Smith JE, Kolowski JM, Graham K, et al (2008) Social and ecological determinants of fissionfusion dynamics in the spotted hyaena. Anim Behav 76:619-636. https://doi.org/10.1016/j.anbehav.2008.05.001

Swanson A, Arnold T, Kosmala M, et al (2016) In the absence of a "landscape of fear": How lions, hyenas, and cheetahs coexist. Ecol Evol 1-12. https://doi.org/10.1002/ece3.2569

Swanson A, Caro TM, Davies-Mostert HT (2014) Cheetahs and wild dogs show contrasting patterns of suppression by lions. Journal of Animal Ecology 83:1418-1427

Tambling CJ, Belton LE (2009) Feasibility of using proximity tags to locate female lion Panthera leo kills. Wildlife Biol 15:435-441. https://doi.org/10.2981/09-029

Tambling CJ, Laurence SD, Bellan SE, et al (2012) Estimating carnivoran diets using a combination of carcass observations and scats from GPS clusters. J Zool 286:102-109. https://doi.org/10.1111/j.1469-7998.2011.00856.x 
659

660

661

662

663

664

665

666

667

668

669

670

671

672

673

674

675

676

677

678

679

680

681

682

683

684

685

Thrash I, Theron GK, du P Bothma J (1995) Dry season herbivore densities around drinking troughs in the Kruger National Park. Journal of Arid Environments 29:213-219. https://doi.org/10.1016/s0140-1963(05)80091-6

Trinkel M, Kastberger G (2005) Competitive interactions between spotted hyenas and lions in the Etosha National Park, Namibia. Afr J Ecol 43:220-224

Valeix M (2011) Temporal dynamics of dry-season water-hole use by large African herbivores in two years of contrasting rainfall in Hwange National Park, Zimbabwe. J Trop Ecol 27:163-170. https://doi.org/10.1017/S0266467410000647

Valeix M, Loveridge AJ, Chamaillé-Jammes S, et al (2009) Behavioral adjustments of African herbivores to predation risk by lions: Spatiotemporal variations influence habitat use. Ecology 90:23-30. https://doi.org/10.1890/08-0606.1

Valeix M, Loveridge AJ, Davidson Z, et al (2010) How key habitat features influence large terrestrial carnivore movements: waterholes and African lions in a semi-arid savanna of north-western Zimbabwe. Landscape Ecology 25:337-351. https://doi.org/10.1007/s10980-009-9425-x

van Dijk J, Gustavsen L, Mysterud A, et al (2008) Diet shift of a facultative scavenger, the wolverine, following recolonization of wolves. J Anim Ecol 77:1183-1190. https://doi.org/10.1111/j.1365-2656.2008.01445.x

Vanak AT, Fortin D, Thaker M, et al (2013) Moving to stay in place: behavioral mechanisms for coexistence of African large carnivores. Ecology 94:2619-2631. https://doi.org/10.1890/13-0217.1

Watts HE, Blankenship LM, Dawes SE, Holekamp KE (2010) Responses of Spotted Hyenas to Lions Reflect Individual Differences in Behavior. Ethology 116:1199-1209. https://doi.org/10.1111/j.1439-0310.2010.01833.x

Wilson EE, Wolkovich EM (2011) Scavenging: how carnivores and carrion structure communities. Trends Ecol Evol 26:129-135. https://doi.org/10.1016/j.tree.2010.12.011 


\section{FIGURES CAPTIONS}

687 Figure 1: a) Rules for attributing attraction scores to simultaneous steps of hyaenas and lions

688 before and after and encounter. The figure presents an example of movement of species A

689 (circles) and B (stars) 4h before their encounter. Darker grey areas characterize strong

690 attraction (score +1) of species A to species B (or to location of species B) while light grey

691 show mild attraction (score +0.5). Squared hashed areas show strong avoidance (score -1 ) of

692 species B (or of location of species B) by species A and grey hashed areas represent areas of

693 mild avoidance (score -0.5). Areas of strong and mild attraction/avoidance are based on

694 threshold angles of $\alpha=10^{\circ}$ and $\beta=30^{\circ}$ respectively. In any other case, species A was considered

695 as moving independently from species B.

696 b) Example of movement paths of species A (circles) and species B (stars) leading to an

697 encounter with overall attraction computed for the 4 hours preceding the encounter as the sum

698 scores of all steps from both species.

699 Figure 2: Distribution of the 100 proximity indices randomly generated compared to the

700 proximity index computed from actual GPS data (black vertical line).

701 Figure 3: a) Monthly distribution of encounters between hyaenas and lions depending on the

702 presence or absence of a carcass.

703 b) Effect of distance to water of the probability of encounter in the presence and absence of a 704 carcass.

705 c) Duration of encounters between hyaenas and lions depending on the presence or absence of 706 a carcass.

707 Figure 4: Creation and outcome of encounters occurring in the presence versus absence of a 708 carcass between hyaenas and lions. 


\section{FIGURE 1A}

a

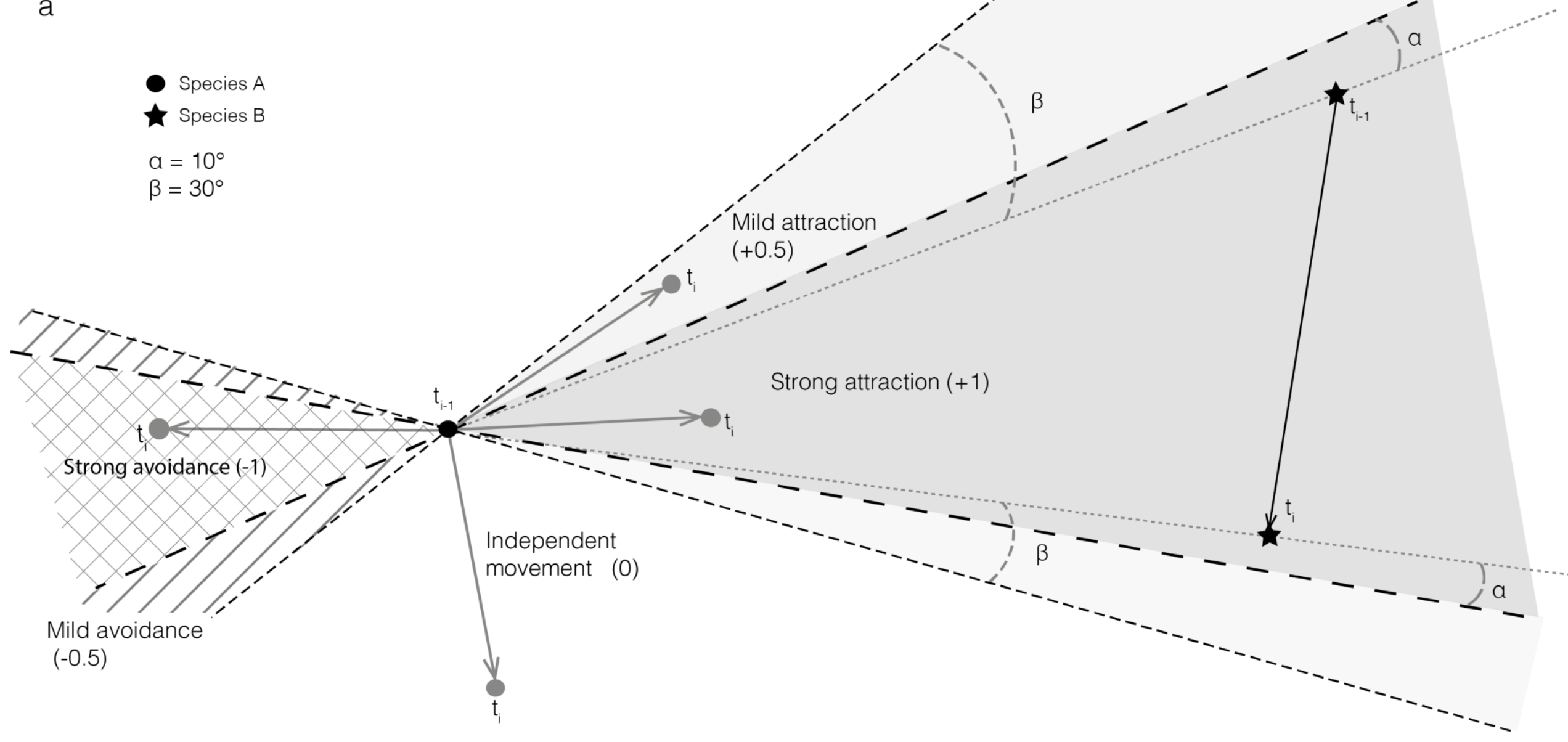

Reference lines to compute the angles $\alpha$ and $\beta$

Possible movement of species $A$ between $t_{i-1}$ and $t_{i}$

- - - Lines defining areas of strong attraction or avoidance Realised movement of species $B$ between $t_{i-1}$ and $t_{i}$ Lines defining areas of mild attraction or avoidance 


\section{FIGURE 1B}

b

- Species A

^ Species B

$a=10^{\circ}$

$\beta=30^{\circ}$

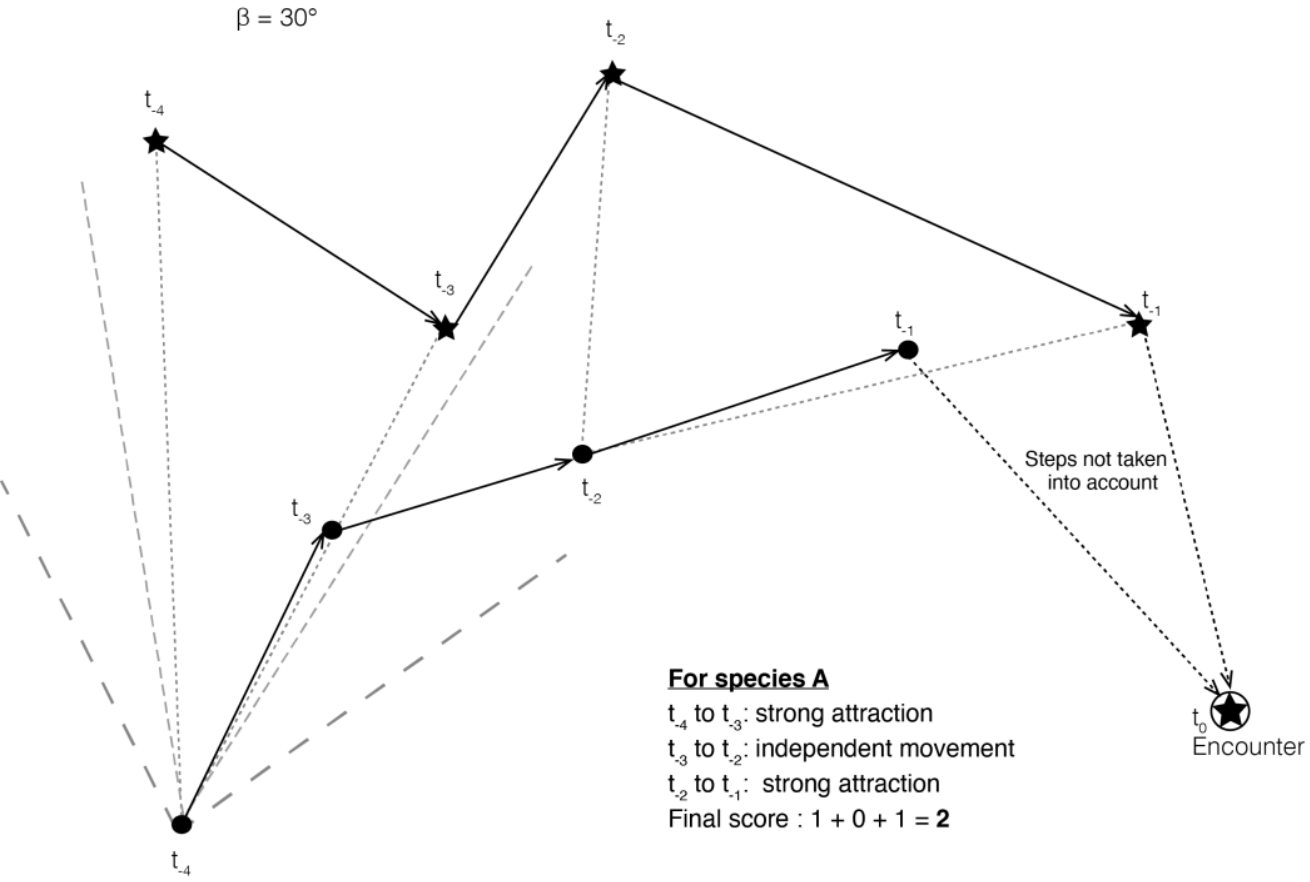

712

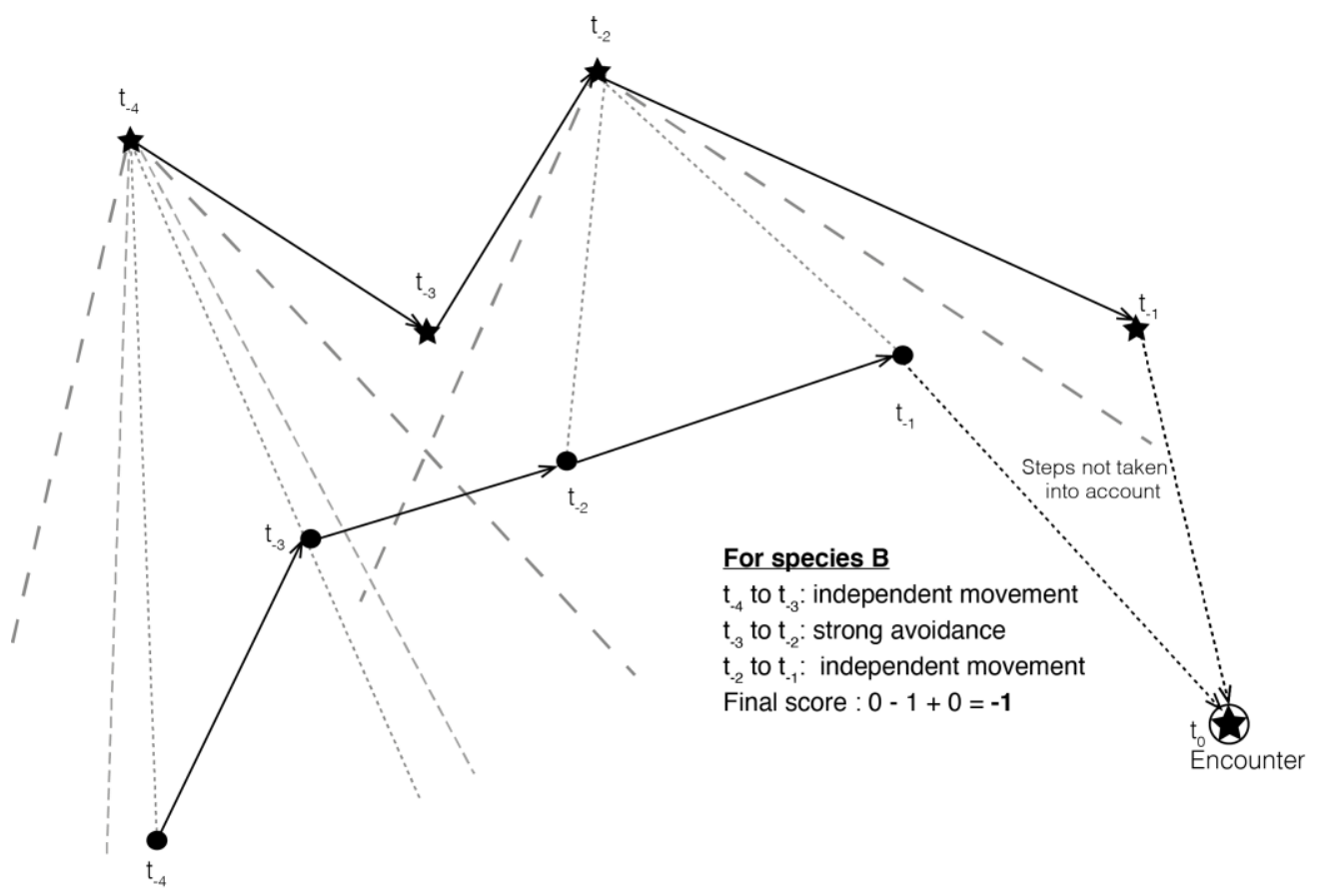




\section{Figure 2}

714

715

Average proximity index 0.0011

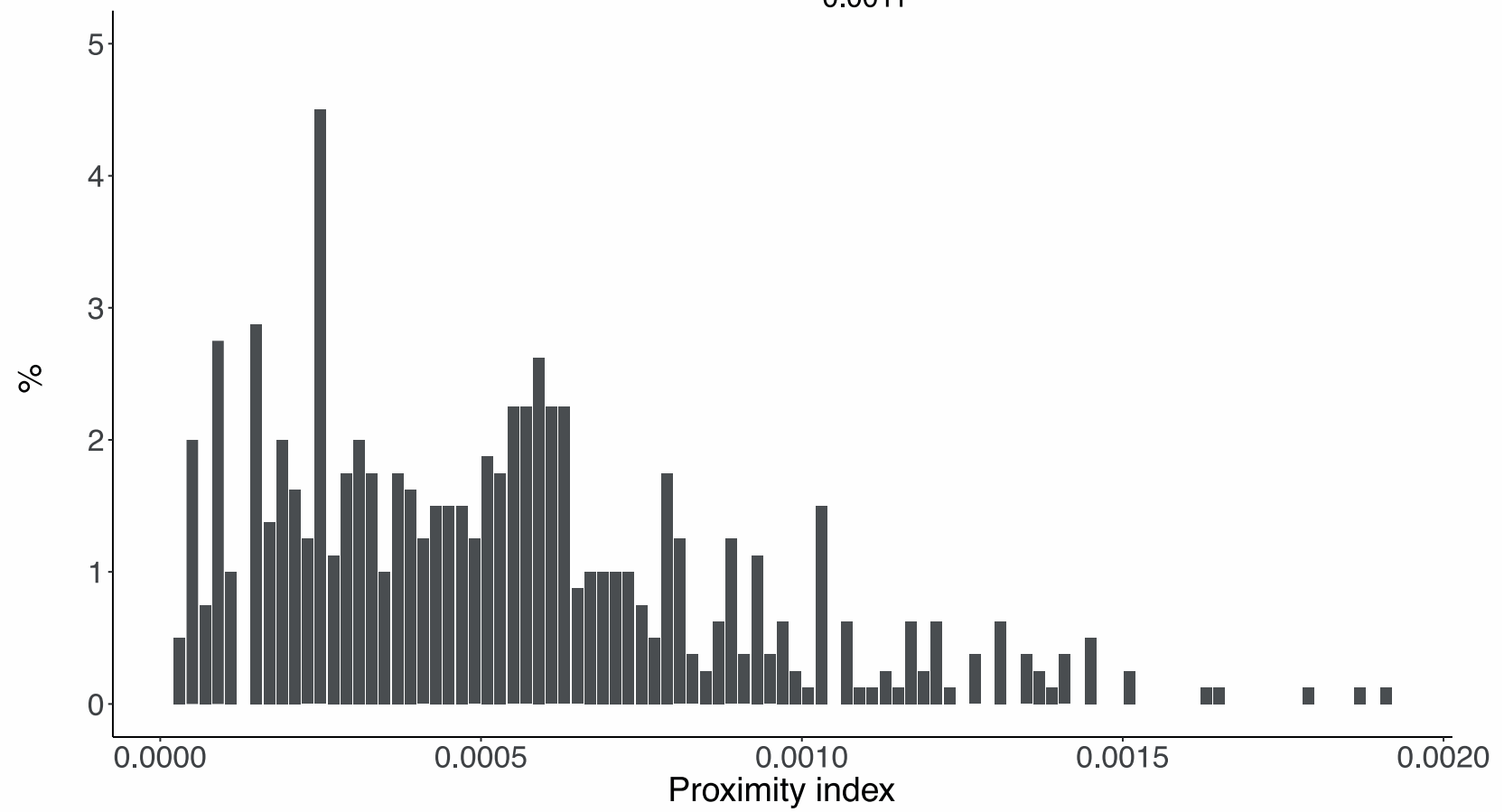



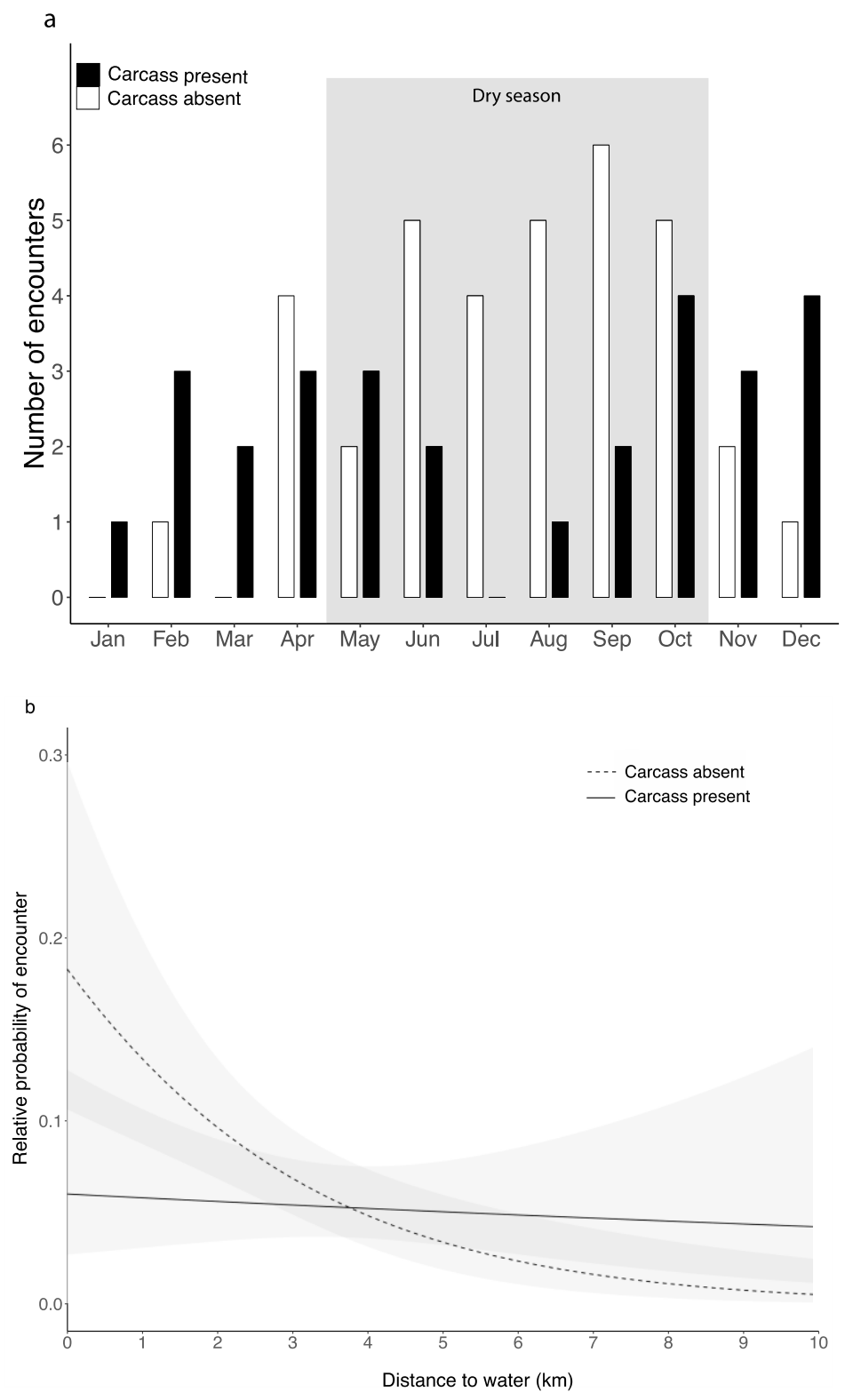

c

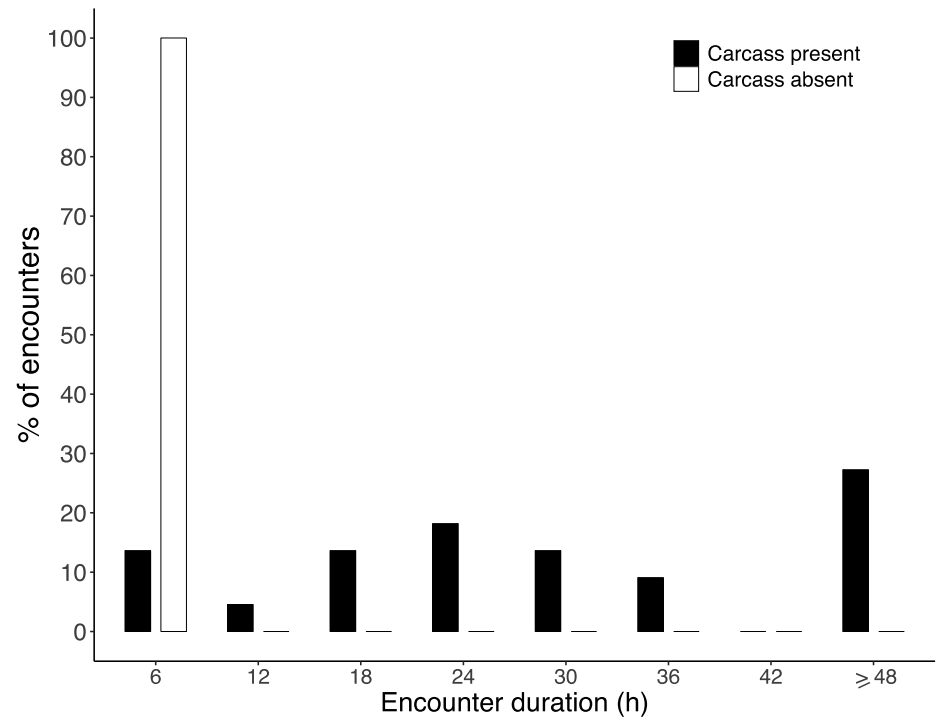


Encounters in the PRESENCE of a carcass $(n=28)$

Lion arrived at carcass first in 20 cases

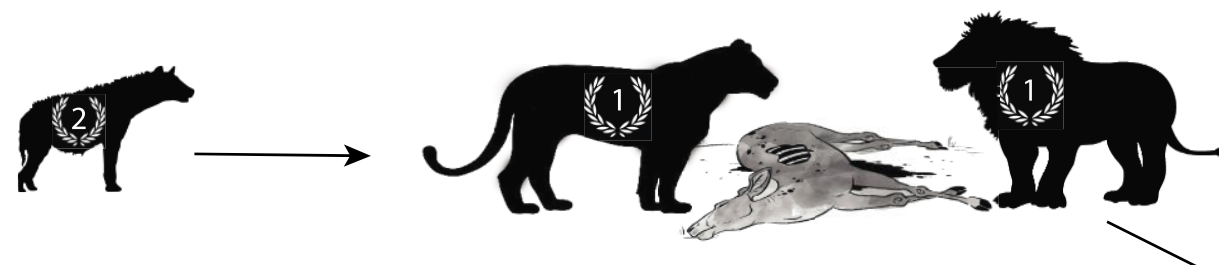

Hyaena arrived at carcass first in 7 cases

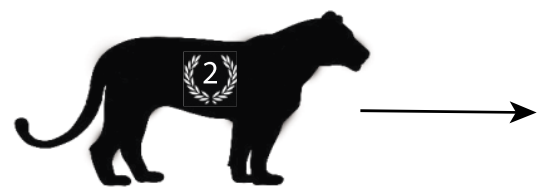

ALL cases involved only lionesses

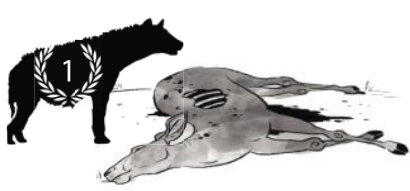

Lion dominant in 18 cases $(n=20)$
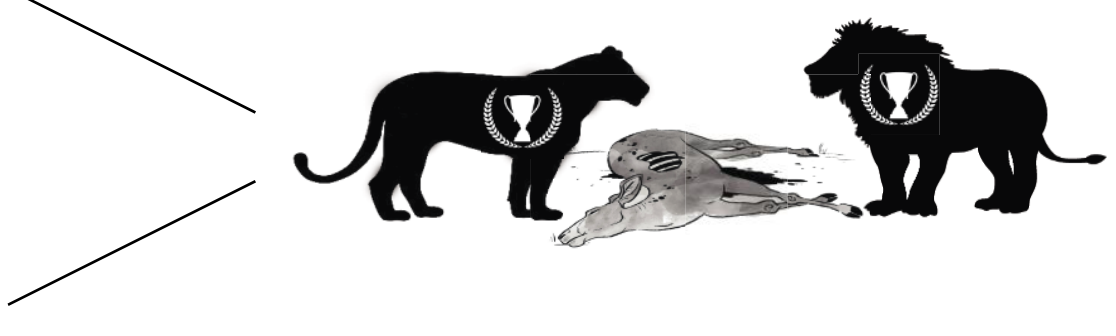

Encounters in the ABSENCE of a carcass ( $n=35$ )

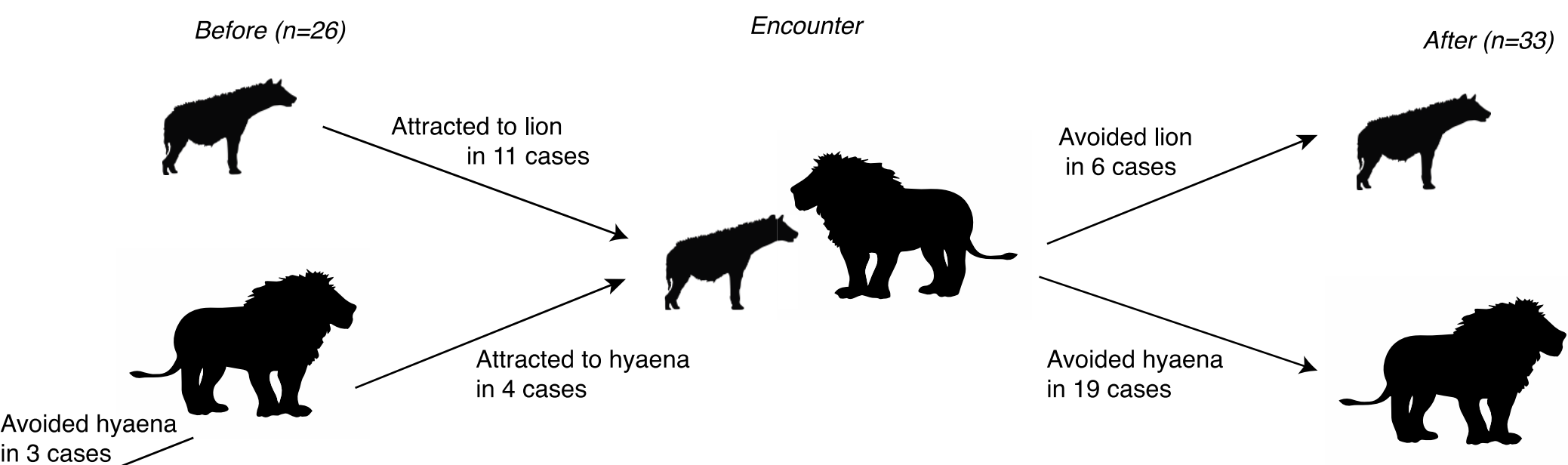

in 3 cases

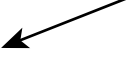

